\title{
A Study on the Characteristics of the Heavy Rainfall Events in Honam District along the Border of mT Airmass
}

\author{
Se-Hwan Yang ${ }^{1}$ and Chan-Su Ryu ${ }^{2 \dagger}$
}

\begin{abstract}
District of Korea affected by westerly wind and heavy rainfall is predominantly distributed in the west and south of Honam district. So, this study is becoming a necessity. In this study, it is investigated that the characteristics of heavy rainfall occurred frequently in Honam district along the border of $\mathrm{mT}$ airmass after the end of rainy season due to atmospheric instability, lower $(850 \mathrm{hPa})$ convergence and topographic effect. Our results show that heavy rainfall occurred in Honam district along the border of $\mathrm{mT}$ airmass results from the appropriate mechanism of the unstable vertical structure and moisture flux in the expansion and contraction of the border of $\mathrm{mT}$ airmass. All things considered, the improvement of the predictability of heavy rainfall occurred in Honam district along the border of $\mathrm{mT}$ airmass could be possible by the generalization of the results of this study.
\end{abstract}

Key words: Precipitation, Heavy Rainfall, Atmospheric Instability, KLAPS

\section{Introduction}

One of the most important components is the precipitation to retain the environment and life of mankind. We are being damaged by the unsuitable amounts of rainfall ${ }^{[1]}$. Floods and landslides occurred every year because of heavy rainfall in a short time, so this is one of the greatest weather disasters in our country as a interest of social phenomenon ${ }^{[2,3]}$. District of our country affected by westerly wind and heavy rainfall is predominantly distributed in the west and south coast of Honam region ${ }^{[4]}$. Therefore, this study is becoming a necessity due to damage frequently occurred by heavy rainfall.

\section{Data and Analysis Method}

The precipitation data, of which investigation period is the recent 10 years(2000-2009), are used in this study. Fig. 1 shows a distribution of the meteorological stations in Honam region. The heavy rainfall, frequently occurred in Honam region due to atmospheric instabil-

${ }^{1}$ Institute of Atmospheric Physics, Chinese Academy of Sciences, China ${ }^{2}$ Dept. of Earth Sci. Edu. Chosun Univ. 309 Pilmun-daero Dong-gu Gwangju 501-759, Korea

†Corresponding author : csryu@chosun.ac.kr

(Received : November 11, 2012, Revised : December 15, 2012, Accepted : December 21, 2012) ity along the border of $\mathrm{mT}$ airmass, was divided to analyze its characteristics into following elements. There are two types of heavy rainfall. One is the heavy rainfall occurred along the contracted border of $\mathrm{mT}$ airmass. The other is the heavy rainfall occurred along the expanded border of $\mathrm{mT}$ airmass. The rainfall amount of each district of the former is shown in Table 1. The rainfall amount of each district of the latter is shown in Table 2. To investigate the synoptic characteristics of

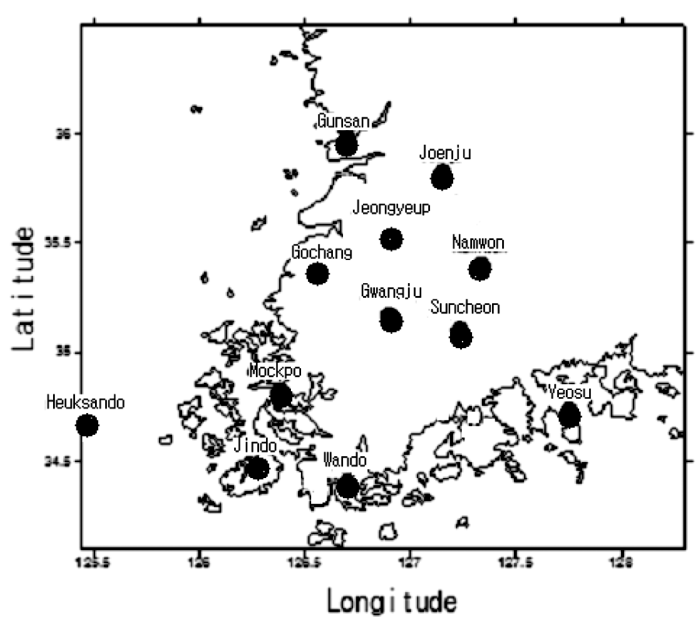

Fig. 1. The meteorological stations of precipitation in Honam district. 
Table 1. List of heavy rainfall events along the border of contracted $\mathrm{mT}$ airmass occurred in Honam district during the recent 10 years(2000 2009).

\begin{tabular}{cccc}
\hline Date & Station & $\begin{array}{c}\text { Rainfall amounts } \\
(\mathrm{mm} / \text { day })\end{array}$ & $\begin{array}{c}\text { Maximum amount of hourly } \\
\text { rainfall(mm/hour })\end{array}$ \\
\hline Aug.04.2000 & Suncheon & 167.5 & 57.5 \\
Aug.08.2000 & Gwangju & 41.2 & 32.2 \\
Aug.06.2002 & Suncheon & 105.0 & 37.5 \\
Aug.07.2003 & Yeosu & 70.0 & 44.5 \\
Aug.23.2004 & Yeosu & 113.0 & 31.0 \\
Aug.01.2005 & Wando & 50.5 & 30.9 \\
Aug.02.2005 & Jindo & 97.5 & 54.5 \\
Aug.03.2005 & Joenju & 249.5 & 57.0 \\
Aug.11.2005 & Gunsan & 58.5 & 32.0 \\
Aug.27.2006 & Gwangju & 108.0 & 38.0 \\
Aug.07.2007 & Yeosu & 82.0 & 38.0 \\
Oct.07.2007 & Heuksando & 144.5 & 42.5 \\
Jul.23.2008 & Joenju & 47.0 & 32.0 \\
\hline
\end{tabular}

Table 2. List of heavy rainfall events along the border of expanded $\mathrm{mT}$ airmass occurred in Honam district during the recent 10 years(2000-2009)

\begin{tabular}{cccc}
\hline Date & Station & $\begin{array}{c}\text { Rainfall amount } \\
(\mathrm{mm} / \text { day })\end{array}$ & $\begin{array}{c}\text { Maximum amount of hourly } \\
\text { rainfall(mm/hour })\end{array}$ \\
\hline Aug.07.2000 & Suncheon & 63.5 & 48.5 \\
Aug.31.2000 & Suncheon & 81.0 & 32.5 \\
Aug.26.2001 & Suncheon & 47.0 & 41.0 \\
Aug.12.2002 & Namwon & 97.5 & 31.5 \\
Aug.27.2003 & Gwangju & 104.0 & 54.5 \\
Aug.22.2004 & Gwangju & 123.0 & 40.5 \\
Sep.01.2005 & Joengyeup & 139.0 & 70.0 \\
Aug.06.2006 & Namwon & 33.5 & 30.5 \\
Aug.24.2006 & Namwon & 59.5 & 52.0 \\
Aug.25.2006 & Gwangju & 104.0 & 34.5 \\
Aug.05.2007 & Jindo & 105.0 & 38.0 \\
Jun.02.2008 & Gunsan & 63.5 & 33.5 \\
Aug.08.2008 & Gwangju & 98.0 & 73.5 \\
Aug.07.2009 & Joengyeup & 120.0 & 32.0 \\
\hline
\end{tabular}

the heavy rainfall occurred along the border of $\mathrm{mT}$ airmass, surface weather chart, assistance weather chart and KLAPS(Korea Local Analysis and Prediction System) were used. The significant similarities were found from the results of comparison of all cases through distribution of heavy rainfall, type of pressure pattern, southwest stream flow, vorticity, equivalent potential temperature, and so on. Therefore, we selected one of each case as a representative to contribute to improvement of the predictability of the heavy rainfall occurred along the border of $\mathrm{mT}$ airmass, relatively lower than others(changma front, typhoon, cyclone), with this study based on following results.

\section{Results and Discussion}

\subsection{Heavy Rainfall Occurred in Honam District} along the Border of Contracted mT Airmass

\subsubsection{Precipitation}

The number of events of the heavy rainfall during the last 10 years is 13 . The heavy rainfall (Aug. 27, 2006) occurred in Honam district was selected as a represent- 
ative case. The precipitation of the case was $108 \mathrm{~mm} /$ day and $38 \mathrm{~mm} /$ hour(not shown).

\subsubsection{Surface Weather Chart}

The surface weather chart has been used for the prediction of the state and changing of the weather as a primary weather chart. Weather chart on Aug. 27, 2006 (Fig. 2) shows that the cyclone located in the north of the Korean peninsula is constrained to move toward the east and seems to be getting stronger by the anticyclone located in China. In this process, it seems to increase the degree of atmospheric instability of Honam district located along the border of contracted $\mathrm{mT}$ airmass. The border of the $\mathrm{mT}$ airmass also seems to be contracted.

\subsubsection{Assistance Weather Chart}

Assistance weather chart has a couple of different charts, but we will focus on the chart made by RDAPS(Regional Data Assimilation and Prediction System) in this study. Assistance weather chart on Aug. 27, 2006 is shown in Fig. 3. Moisture flux on $850 \mathrm{hPa}$ ((a) in Fig. 3) shows that continuous southwest stream flows result in the supply of the moisture to Honam district. It has influence on the possibility of the atmos- pheric instability of Honam district and developing of the nimbus. $850 \mathrm{hPa}$ streamline and isotach ( $>25 \mathrm{kts}$ ) ((b) in Fig. 3) shows that area of the strong winds appears in the south of the korean peninsula. Particularly, strong winds higher than $50 \mathrm{kts}$ appears in Jeonbuk district. 850-500 hPa SSI (Showalter Stability Index)((c) in Fig. 3) shows that SSI (-3) covering the Korean peninsula results in the increase of the possibility of developing thunderstorm. It indicates a atmospheric instability. K-index(5)((d) in Fig. 3) shows Kindex of 30 covering the Korean peninsula and a part of China except southwest coast of Honam district. Kindex higher than 40, appearing in the southwest coast of Honam distirct, results in relatively high possibility of rainfall. Vertical Velocity(hPa/hour) on $700 \mathrm{hPa}((\mathrm{e})$ in Fig. 3) shows that strong vertical velocity(-50), being spread out on the Korean peninsula from the southwest coast of Honam district to the northeast of North Korea, results in the convectional rainfall by vertical convection. $850 \mathrm{hPa}$ convergence $(10 \mathrm{E}-6 / \mathrm{sec})$ and isotach $(>25 \mathrm{kts})((\mathrm{f})$ in Fig. 3) shows that the belt of convergence appears in most parts of south Korea. Particularly, the critical value of the Honam district is -74 . Accordingly, developing of the nimbus is caused by vertical ascending air current.

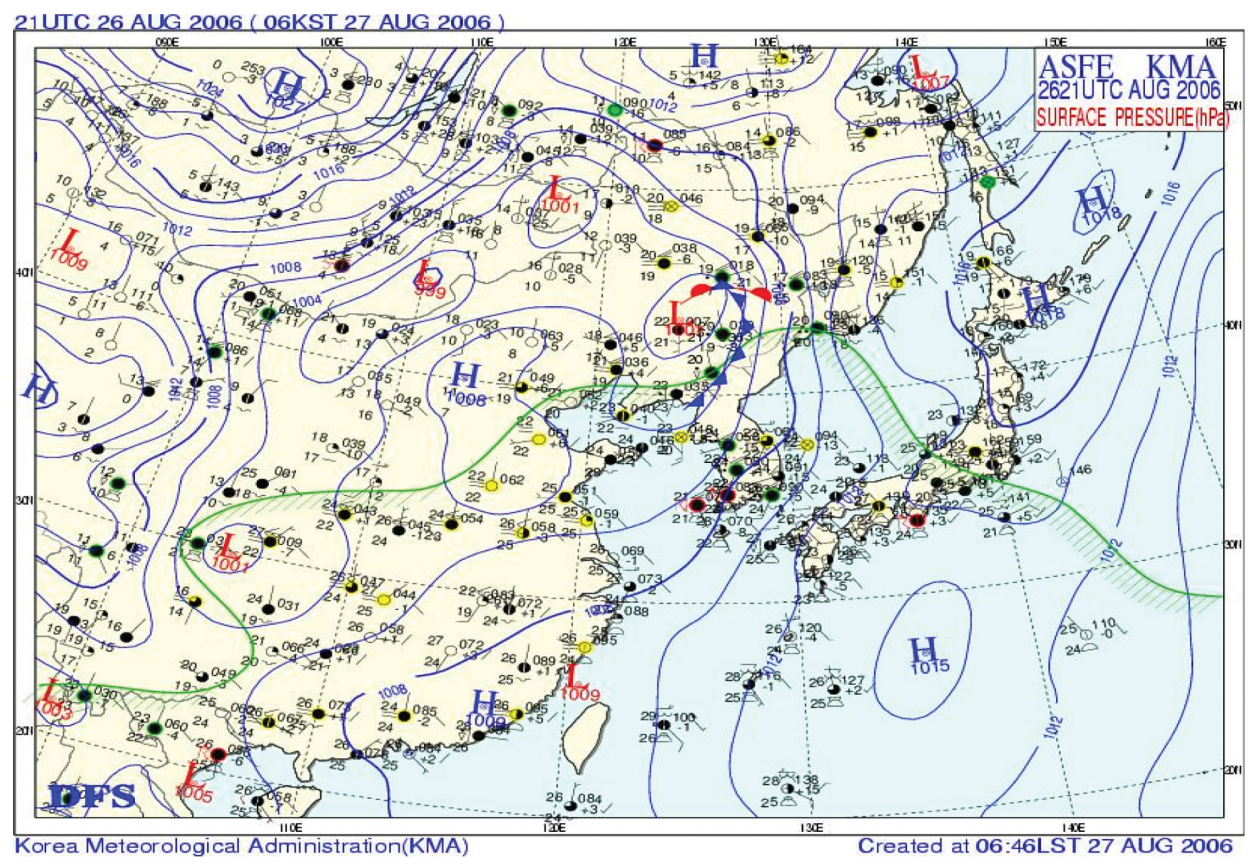

Fig. 2. The surface weather chart on 21 UTC Aug. 27, 2006. 

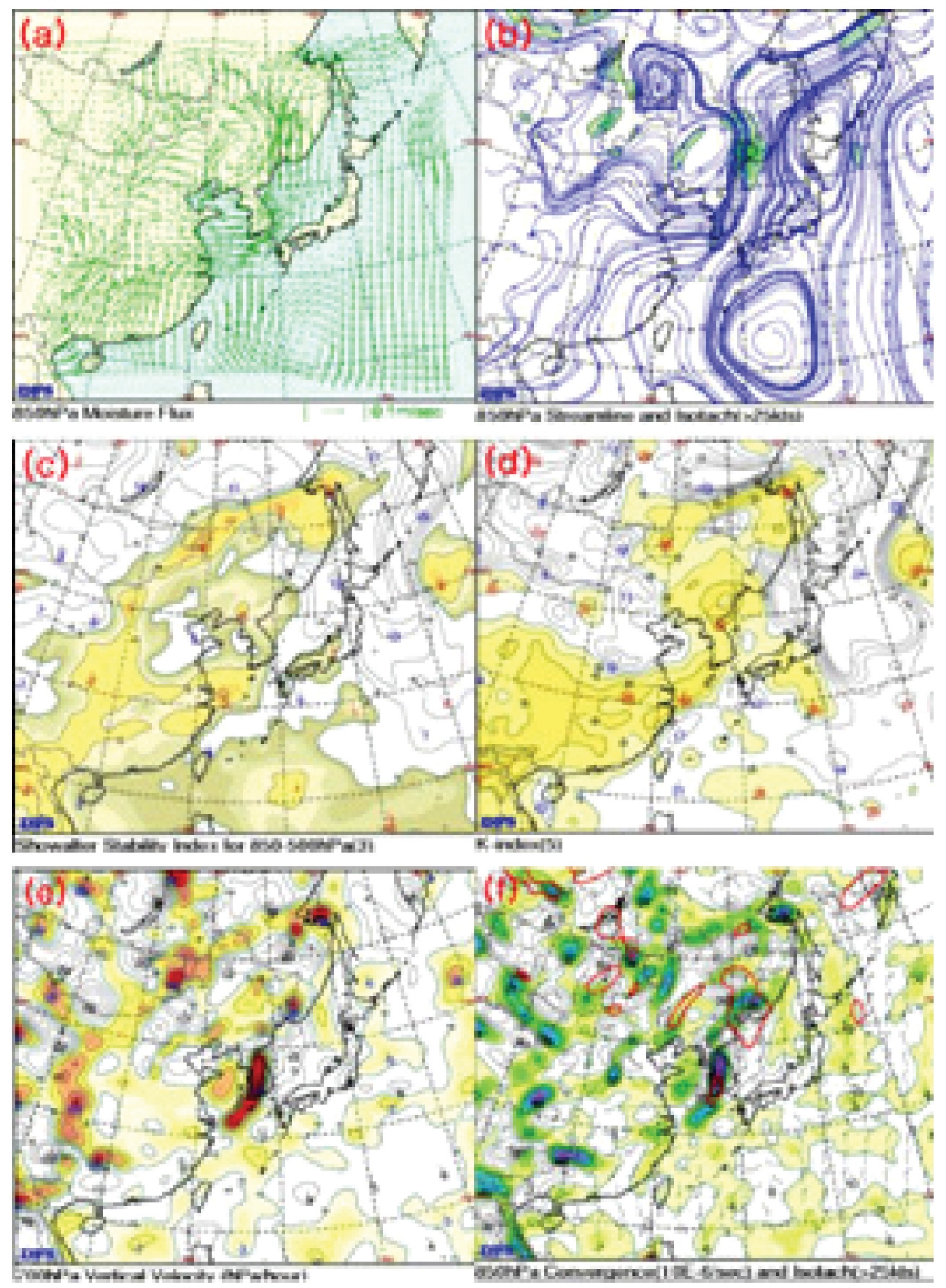

Fig. 3. The assistance weather chart on 00UTC Aug. 27, 2006.

\subsubsection{KLAPS}

In this study, we planned to analyze the synoptic characteristics of heavy rainfall occurred in Honam district along the border of contracted $\mathrm{mT}$ airmass, with
KLAPS(Korea Local Analysis and Prediction System ) data from the vertical cross section of around Gwangju (Fig. 4). Fig. 4 shows the data, worked out every two hours from 18UTC(a) to 22UTC(c) Aug. 26, 2006, 

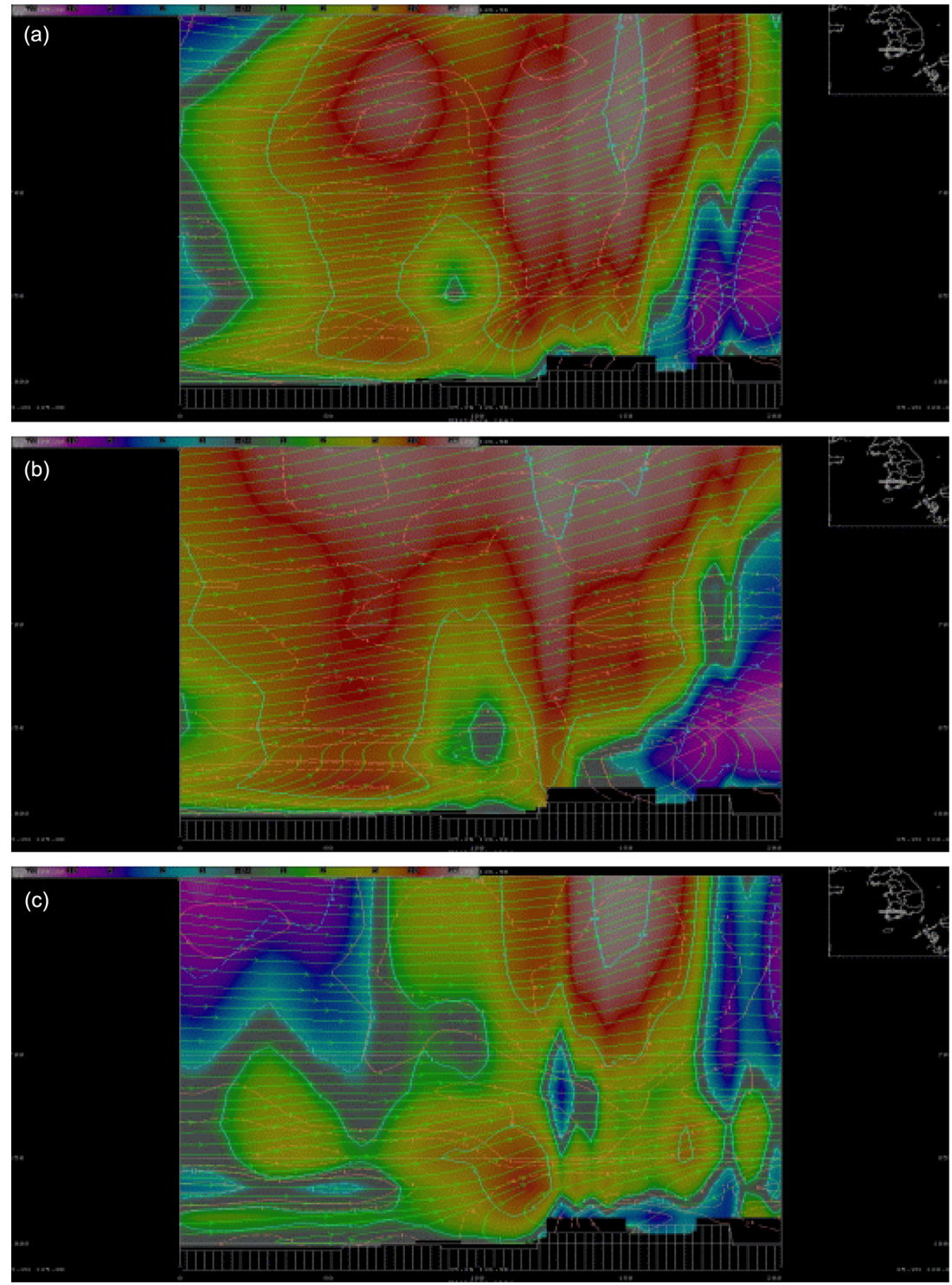

Fig. 4. The Omega, Divergence, vertical circulation of the East and West in Gwangju district on (a) 18UTC, (b) 20UTC and (c) 22UTC Aug. 26, 2006

including vertical Circulation, Divergence and Omega. The vertical circulation of most parts has a northerly direction, but there is a vertical circulation as a small vortex in the middle of two large mountains. Severe weather appears in the west of Honam district due to convergence field occurred in the lower atmosphere. In contrast, divergence field appears in the mountain of the east of Honam district without severe weather. Fig. 4 also shows that positive omega appears in the west of
Honam district. It results in the severe weather occurred by ascending air current. In contrast, negative omega appears in the mountain of the east of Honam district. It results in the descending air current. Over time, heavy rainfall has been caused by convergence in the lower atmosphere, divergence in the upper atmosphere and positive omega. Since then, the weather is clearing up, because of the descending air current resulting from the negative omega. 
3.2 Heavy Rainfall Occurred in Honam District along the Border of Expanded mT Airmass

\subsubsection{Precipitation}

The number of events of the heavy rainfall during the last 10 years $(2000-2009)$ is 14 . The heavy rainfall (Aug. 25, 2006) occurred in Honam was selected as a representative case. The precipitation of the case was $104 \mathrm{~mm} /$ day and $34.5 \mathrm{~mm} /$ hour(not shown).

\subsubsection{Surface Weather Chart}

The weather chart on Aug. 25, 2006(Fig. 5) shows the cyclone located in the southwest of Japan dividing anticyclone into two. There is precipitation caused by atmospheric instability in Honam district.

\subsubsection{Assistance Weather Chart}

The assistance weather chart on Aug. 25, 2006 is shown in Fig. 6. Moisture flux on $850 \mathrm{hPa}((\mathrm{a})$ in Fig.6) shows that continuous stream flows from the North Pacific results in the supply of the moisture through the west coast. It has influence on the possibility of the atmospheric instability of Honam district. $850 \mathrm{hPa}$ streamline and isotach $(>25 \mathrm{kts})((\mathrm{b})$ in Fig. 6) shows that some of the strong winds appear in the east of China. Some of those streamlines flow into the west of
Honam district. SSI on $850-500 \mathrm{hPa}$ ((c) in Fig. 6) shows SSI(less than 0) covering the Korean peninsula. Particularly, SSI(-2) in the Honam district and west coast results in the increase of the possibility of developing thunderstorm. It indicates atmospheric instability. K-index(5)((d) in Fig. 6) shows that K-index of 39, appearing in the west coast of Honam distirct, results in relatively high possibility of rainfall. K-index of 30 appears in the rest of the Korean peninsula. Vertical Velocity(hPa/hour) on $700 \mathrm{hPa}((\mathrm{e})$ in Fig. 6) shows that strong vertical velocity located in the west of Honam district results in the developing of the nimbus by vertical convection. $850 \mathrm{hPa}$ convergence $(10 \mathrm{E}-6 / \mathrm{sec})$ and isotach $(>25 \mathrm{kts})((\mathrm{f})$ in Fig. 6) shows that the belt of convergence appears in the west of Honam district. Particularly, the critical value of the west of Honam district is -31 . Accordingly, developing of the nimbus is caused by vertical ascending air current.

\subsubsection{KLAPS}

Fig. 7 and Fig. 8 show the data, worked out every three hours from 03UTC(a) to 12UTC(c) Aug. 25, 2006, including vertical Circulation, Divergence and Omega. The vertical circulation has a northerly direction, and the belt of convergence appears in the most

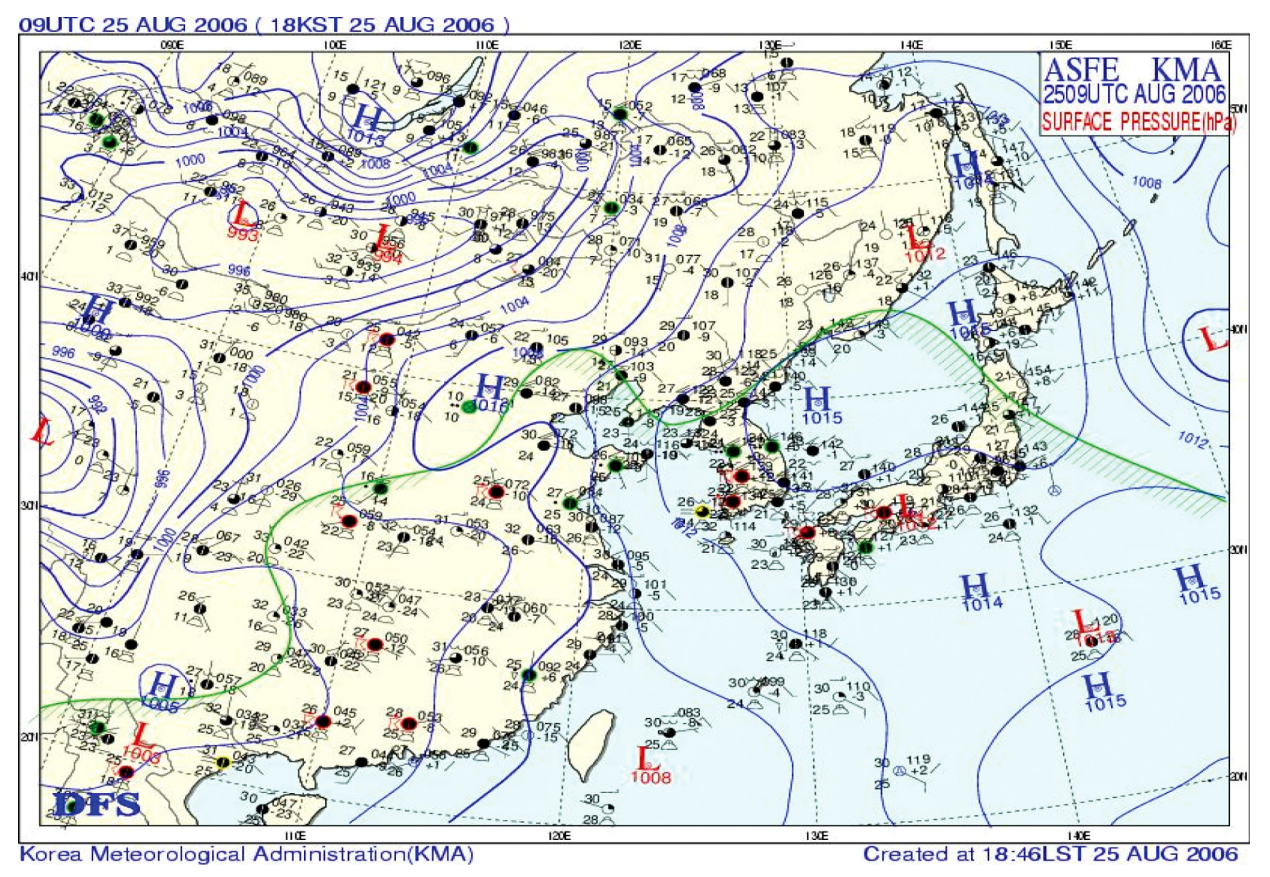

Fig. 5. The surface weather chart on 09UTC Aug. 25, 2006. 

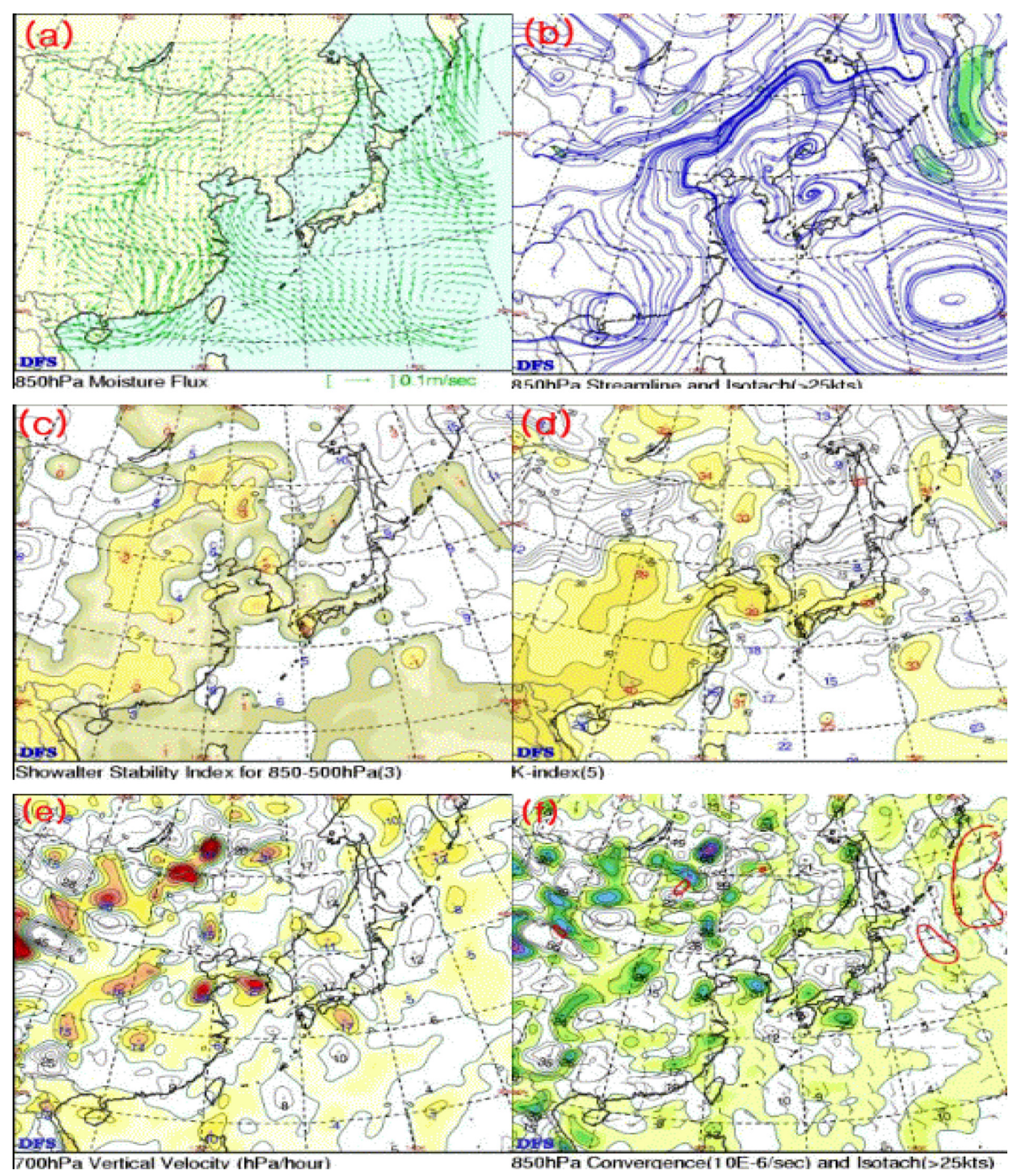

Fig. 6. The assistance weather chart on 00UTC Aug. 25, 2006.
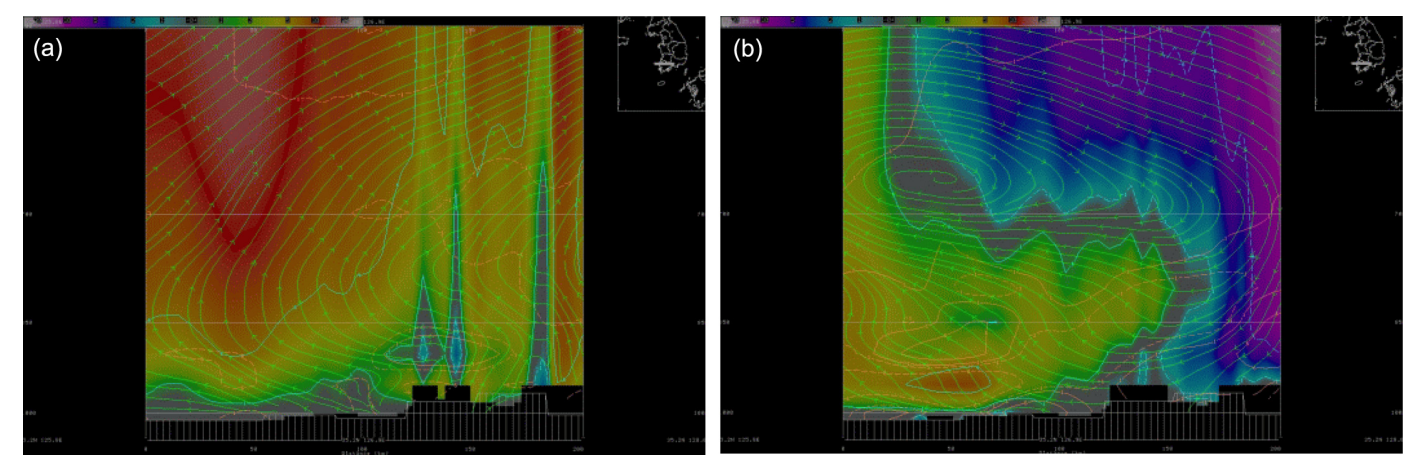

Fig. 7. The Omega, Divergence, Vertival circulation of the East and West in Gwangju district on (a)03UTC, (b)06UTC Aug. 25, 2006. 

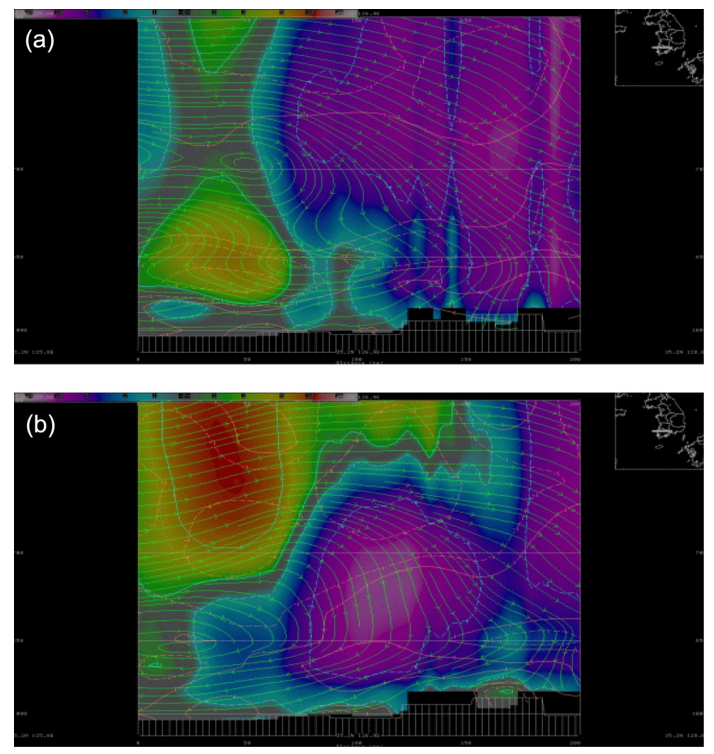

Fig. 8. The Omega, Divergence, Vertival circulation of the East and West in Gwangju district on (a)09UTC, (b)12UTC Aug. 25, 2006.

parts. Severe weather caused by ascending air current due to positive omega appears in the upper atmosphere from the lower atmosphere. Since then, the weather is clearing up, because of the descending air current resulting from the negative omega.

\section{Conclusion}

In this study, it was investigated that the synoptic and asynoptic characteristics of the heavy rainfall occurred in Honam district along the border of $\mathrm{mT}$ airmass during the recent 10years(2000-2009). The heavy rainfall occurred in Honam district along the contracted border of $\mathrm{mT}$ airmass covers most parts of Honam district. The atmospheric instability is shown by the continuous southwest stream flows, and the area of strong winds appears in the west of Honam district. SSI(-3) and Kindex of 40, covering the west of Honam district, result in the increase of the possibility of developing thunderstorm. In addition, Vertical Velocity(hPa/hour) on $700 \mathrm{hPa}$ shows that strong vertical velocity(-50), being spread out on the Korean peninsula from the southwest coast of Honam district to the northeast of North Korea, results in the convectional rainfall by vertical convection. $850 \mathrm{hPa}$ convergence $(10 \mathrm{E}-6 / \mathrm{sec})$ and isotach (>25 kts) shows that the belt of convergence appears in most parts of south Korea. Particularly, the critical value of the Honam district is -74 . Accordingly, developing of the nimbus is caused by vertical ascending air current. KLAPS data from the vertical cross section of around Gwangju show that the atmospheric instability appears in the Honam district due to the existence of vertical circulation, divergence, and positive omega index. The strong winds( $30 \mathrm{kts})$ and large amounts of precipitation result from it.

The heavy rainfall occurred in Honam district along the expanded border of $\mathrm{mT}$ airmass results from the atmospheric instability due to the location of anticyclone expanded to the east of the Korean peninsula. The atmospheric instability is shown by the continuous southwest stream flows, and the area of the strong winds appearing in the west of Honam district. SSI(-2) and $\mathrm{K}$-index of 39, covering the west of Honam district, result in the increase of the possibility of developing thunderstorm. In addition, the strong convergence field appears in the upper atmosphere due to the continuity of atmosphere. KLAPS data show that the atmospheric instability appears in the Honam district due to the existence of vertical circulation, divergence, and positive omega index. The winds(10 30 kts) and heavy rainfall of a part of Honam district result from it.

Our results show that heavy rainfall occurred in Honam along the border of $\mathrm{mT}$ airmass results from the appropriate mechanism of the unstable vertical structure and moisture flux in the expansion and contraction of the border of $\mathrm{mT}$ airmass. The heavy rainfall occurred in Honam district along the border of contracted $\mathrm{mT}$ airmass shows large amounts of the precipitation and the area of the precipitation. The heavy rainfall occurred in Honam district along the border of expanded $\mathrm{mT}$ airmass is affected by the topographic effect, and shows high possibility of the precipitation. All things considered, the improvement of the predictability of heavy rainfall occurred in Honam district along the border of $\mathrm{mT}$ airmass could be possible by the generalization of the results of this study.

\section{Acknowledgment}

This study was supported(in part) by research funds from Chosun University, 2010. 


\section{References}

[1] C. H. Ho, J. Y. Lee, and I. S. Kang, "Climate regime shift in the summertime rainfall in Korea", J. Korean Meteor. Soc., Vol. 36, pp. 334-338, 2000.

[2] D. K. Lee and S. Y. Hong, "Numerical experiments of the heavy rainfall event occurred over Korea during 1 3 September 1984”, J. Korean Meteor. Soc., Vol. 25, pp. 233-266, 1989.
[3] S. U. Park, C. H. Joung, S. S. Kim, D. K. Lee, S. C. Yoon, Y. K. Jeong, and S. G. Hong, "Synoptic scale features of the heavy rainfall occurred over Korea", J. Korean Meteor. Soc., Vol. 22, pp. 42-81, 1986.

[4] S.U. Park, I. H. Yoon, and S. K. Chung, "Heat and moisture sources associated with the changma front during the summer of 1978", J. Korean Meteor. Soc., Vol. 22, pp. 1-27, 1986. 